\title{
Cell kinetics analysis of background colonic mucosa of patients with intestinal neoplasms by ex vivo autoradiography
}

\author{
S NAKAMURA, I KINO, AND S BABA \\ From the Department of Pathology, Okayama University Medical School, Okayama, and First Department of \\ Pathology and Second Department of Surgery, Hamamatsu University School of Medicine, Hamamatsu, Japan
}

SUMMARY Studies of the cell kinetics of the colonic crypts could explain the morphogenesis of colonic adenomas and results suggest that a derangement of the proliferative zone of the colonic crypts takes place before adenoma development. This study was conducted to determine whether this is the case or not. The labelling distribution and labelling index (LI) of the colonic crypts was examined with ex vivo autoradiography. Eight patients with intestinal neoplasms, three with familial polyposis coli, four with ordinary colon cancer, and one with two colonic adenomas. Similar labelling distributions and absent upward shift of the active proliferative zone in crypts were observed in patients with familial polyposis and in those with non-polyposis cancer, or adenomas. The non-proliferative zone of the crypts was well preserved in all eight patients. The mean of the labelling index of the three patients with familial polyposis coli was $8 \cdot 35 \%(3 \cdot 17)$, values expressed as means (SD) and that of the five patients with non-polyposis cancer, or adenomas was 8.55\% (3.20). None of the eight patients showed derangement of the proliferative zone of colonic crypts. This result is compatible with the hypothesis that adenomas are detected first as 'buds of adenomas', which sprout into the lamina propria mucosae in the middle part of normal crypts.

The mechanism of development of colonic adenomas is controversial. Several workers have proposed that expansion or shift of the proliferative zone of colonic crypts occurs before adenoma development, ${ }^{1-5}$ while others have suggested that adenomas develop from the normal proliferative zone in the lower half of the colonic crypts. ${ }^{67}$ If the former proposal is correct, abnormal distribution of labelling in the crypts should be seen more often in patients with familial polyposis coli (FPC) than in those without polyposis.

We have studied the morphogenesis of colonic adenomas in four patients with familial polyposis coli by complete serial sectioning of normal appearing colonic mucosa. Consequently, we found that adenomas appeared in the middle part of normal crypts, sprouting into lamina propria mucosae as 'buds of adenomas', after which they moved upward and formed single gland adenomas in the upper part

Address for correspondence: Professor Isamu Kino. First Department of Pathology, Hamamatsu University School of Medicine, 3600 Handacho. Hamamatsu 431-31, Japan.

Received for publication 22 January 1988. of the mucosa ${ }^{8}$ These findings do not support those of the above mentioned reports ${ }^{1-5}$ suggesting that adenomas appear in the upper part of the mucosa after expansion or shift of the proliferative zone of the colonic crypts.

In an earlier study we reported on the use of $e x$ vivo autoradiography, by which we could study the cell kinetics in specimens removed surgically. This method enabled us to observe labelled epithelial cells in the background colonic crypts of a patient with familial polyposis coli and four patients with ordinary colonic cancers.

Upon observation, it appeared that the distribution of labelled cells in the crypts of the patients with familial polyposis coli was similar to that in the patients with ordinary colonic cancers and no labelled cells were seen in the luminal surface epithelium of the background mucosa in any patient. ${ }^{9}$ To confirm these results, we report here the distribution of labelled cells and the labelling index of the background colonic mucosa in patients with or without polyposis by the ex vivo autoradiography method. 
Table 1 Clinicopathological data on the eight patients with intestinal neoplasms examined

\begin{tabular}{|c|c|c|c|c|}
\hline Patient (pathol no) & Age/sex (yr) & Surgical procedure & $\begin{array}{l}\text { Portion subjected to ex vivo } \\
\text { autoradiography }\end{array}$ & Pathological findings \\
\hline 1. HM (81-2807) & $22 / F$ & Total colectomy & Sigmoid colon & FPC with 359 polyps \\
\hline 2. HK (81-3541) & $20 / \mathrm{F}$ & Total colectomy & Sigmoid colon & FPC with 624 polyps \\
\hline 3. IT (81-4139) & $19 / \mathrm{F}$ & Total colectomy & Sigmoid colon & FPC with 1 cancer and 1624 polyps \\
\hline 4. $\mathrm{OC}(81-1775)$ & $57 / F$ & Recto-sigmoidectomy & Sigmoid colon & Adenocarcinoma \\
\hline 5. SS (81-1894) & $57 / \mathrm{M}$ & Recto-sigmoidectomy & Sigmoid colon & Adenocarcinoma \\
\hline 7. HK (81-3791) & $47 / \mathrm{F}$ & Recto-sigmoidectomy & Sigmoid colon & Adenocarcinoma \\
\hline 8. IS (82-225) & $62 / F$ & Left hemicolectomy & Sigmoid colon & Adenocarcinoma \\
\hline
\end{tabular}

FPC: familial polyposis coli.

\section{Methods}

\section{PATIENTS}

Three patients with familial polyposis coli, four with ordinary colonic cancer, and one with two macroscopic adenomas, were examined. Clinicopathological data on these eight cases are shown in Table 1.

EX VIVO AUTORADIOGRAPHY

A modification of the procedure of ex vivo autoradiography was used. ${ }^{9}$ The resected organ was quickly brought to the RI centre from the operating theatre. After the main artery was exposed, a cannula (Medicut 16G, Japan Sherwood, Tokyo) was inserted. Then the organ was placed in a moist chamber at $37^{\circ} \mathrm{C}$, and perfused with 500 to $1000 \mathrm{ml}$ oxygenated perfluorochemical blood substitute (Fluosol-DA 20\%, Green Cross Corp., Osaka) containing 1000-2000 $\mu \mathrm{Ci}\left[{ }^{3} \mathrm{H}\right] \mathrm{dThd}$ (New England Nuclear, USA; specific activity, $20 \mathrm{Ci} / \mathrm{mmol}$ ) through the cannula with the aid of a roller pump (Type ABP02, Asahi Medical Co., Osaka) for about 30 minutes. During the perfusion, arterial pressure was monitored with a sphygmomanometer and kept in the range of $120-140 \mathrm{mmHg}$. Thereafter we reperfused the organ with $500 \mathrm{ml}$ warm saline to wash out residual isotopes from the vessels of the colon. This ex vivo autoradiography was performed between 11 am and $2 \mathrm{pm}$ in order to avoid a possible effect of circadian rhythm.

\section{TISSUE FIXATION AND PREPARATION OF} SECTIONS

After perfusion, the resected colon was irrigated with phosphate-buffered formalin ( $\mathrm{pH} \mathrm{7.0)}$ through one cut end of the colon to prevent desquamation of the surface epithelium. Then the colon was cut open with scissors for observation of its mucosal surface and was fixed in phosphate buffered formalin. Blocks of specimens (up to $4 \mathrm{~cm}$ long and $0.5 \mathrm{~cm}$ thick) were dehydrated, embedded in paraffin, sectioned at $3 \mu \mathrm{m}$, and stained with haematoxylin and eosin ( $\mathrm{H}$ and $\mathrm{E}$ ).

\section{MICROAUTORA DIOGRAPHY}

Deparaffinised sections were dipped in Sakura NR-M2 emulsion (Konishiroku Photo Ind. Co., Tokyo), stored at $4^{\circ} \mathrm{C}$ for six weeks in a dark box over silica gel, developed with an FD-111 developer and stained with $\mathrm{H}$ and $\mathrm{E}$.

ANALYSIS OF CELL KINETICS

Evenly labelled sections were used for cell kinetic studies. Apparently normal colonic crypts located between polyps or more than $4 \mathrm{~cm}$ from regions of càncer were selected. These parts showed no frank pathologic features such as hyperplasia, regeneration or atypia. The crypts, cut longitudinally along their entire length, were then examined. The entire length on either side of the crypt was designated as the "crypt column'. ${ }^{10}$ Therefore, the crypt column was defined as a row of epithelial cells extending from the midpoint at the base of the crypt, through the cryptsurface junction, to the midpoint between adjacent crypts. Well oriented crypt columns were photographed and the length of the crypt and the lengths of regions of densely labelled cells were measured on enlarged prints of 50 crypts columns from each patient.

The fractional position of each labelled cell is expressed as the position length of labelled cells from the bottom of the crypt divided by the length of the crypt column. The number of labelled cells in each 0.04 fractional length of the crypt was calculated as a percentage of the total number of labelled cells in 50 crypt columns and values were represented as histograms of the labelling distribution. The number of labelled cells as a percentage of the total epithelial cells in each column was expressed as the labelling index. Differences in labelling index values were analysed by Student's $t$ test. 

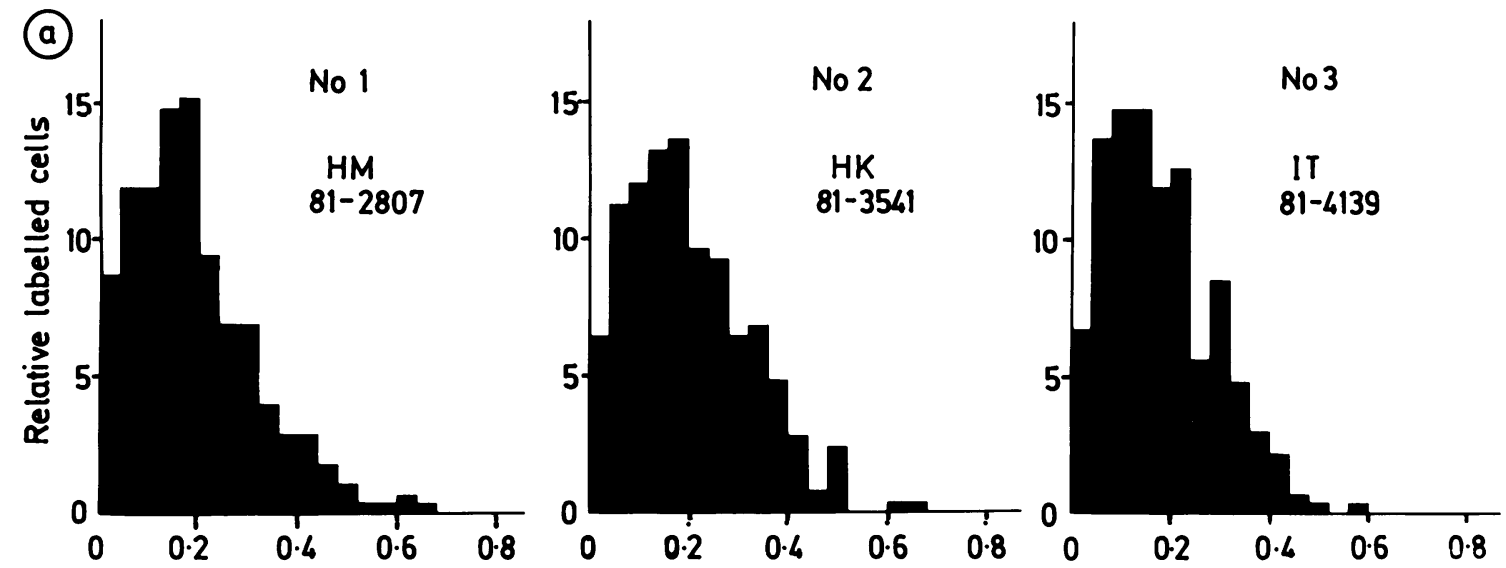

Labelled cell positions of crypt column
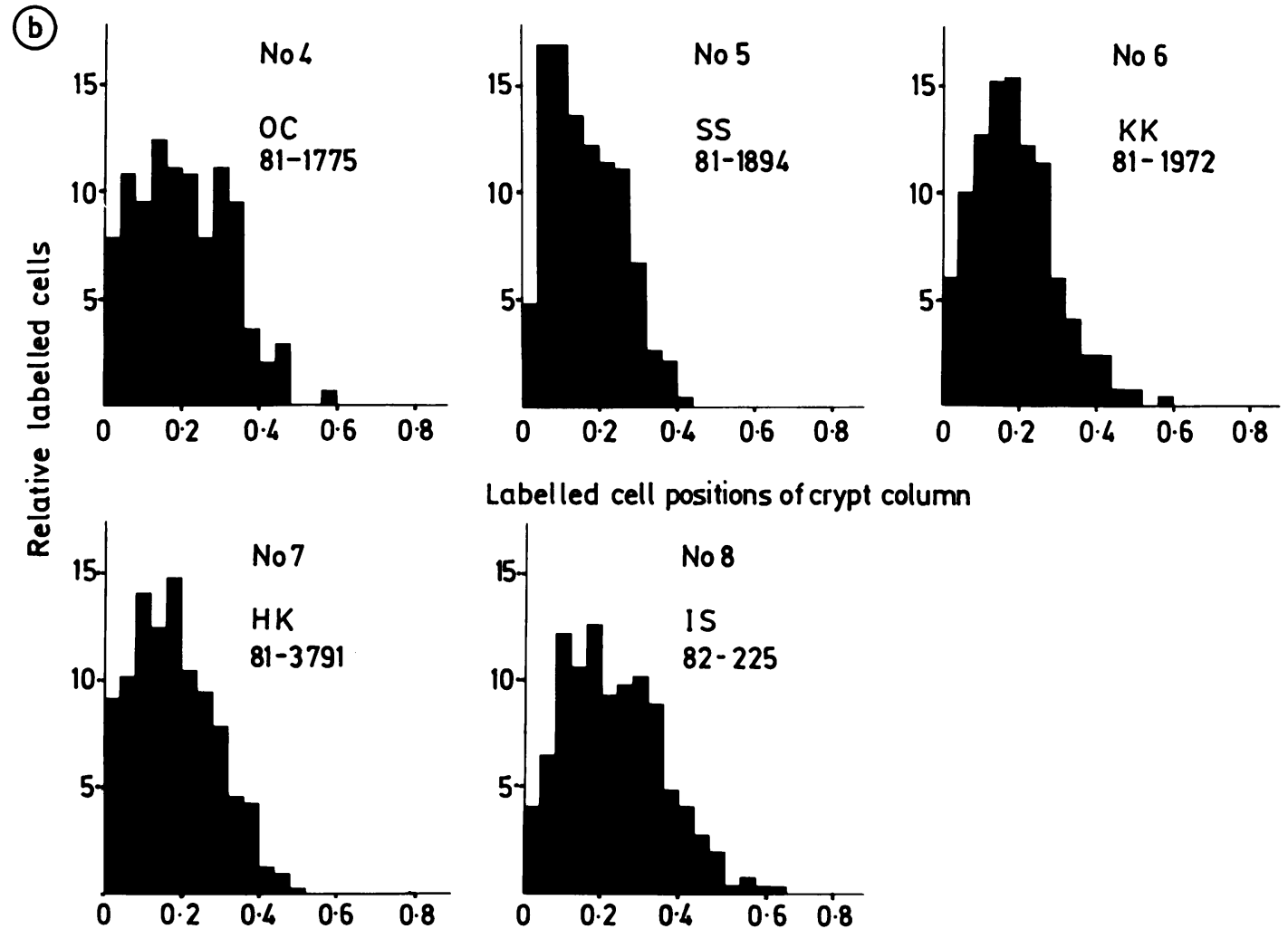

Labelled cell positions of crypt column

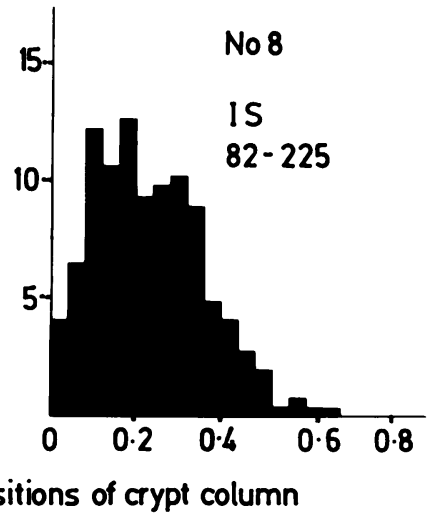

Fig. 1 (a) Histograms show the labelling distribution in colonic crypts of three patients with familial polyposis coli (b) Histograms of labelling distributions in five patients with non-polyposis cancer or adenomas. Abscissa; labelled cell position in the crypt column. Fractional position is defined as the position length of labelled cells from the bottom of the crypt divided by length of the crypt column. Zero indicates the crypt base and $0 \cdot 8$ indicates the upper portion of the crypt near the luminal surface epithelium. Ordinates; percentages of labelled cells in 0.04 fractions of the crypt lengths. 


\section{Results}

Even labelling distribution of the crypts in the background colonic mucosa was observed in three patients with familial polyposis coli (Fig. 1a). Total numbers of 267,250 , and 270 labelled cells were seen in 50 crypt columns in these patients (Table 2). The frequency of labelled cells was less than $10 \%$ at the bottom of the crypt column, but increased significantly within cell position $\mathbf{0} \cdot 20$. Labelled cells were mostly located between the bottom and cell position $0 \cdot 30$. This area is regarded as the zone of active proliferation. ${ }^{10}$ The labelled cells were found most frequently in the fractional position of $0 \cdot 18$ to $0 \cdot 20$. The frequency of labelled cells gradually decreased from cell position 0.30 to 0.70 (transitional zone) and no labelled cells were found between cell position $0 \cdot 70$ and the luminal surface epithelium (non-proliferative zone).

In the five cases of non-polyposis cancer or adenomas, the total numbers of labelled cells ranged from 246 to 369 , and the histograms of these cases were essentially the same as those of the three cases of familial polyposis coli. Three zones, namely, the active proliferative, transitional and nonproliferative zones, could be distinguished in the five cases without polyposis. The labelled cells were present most frequently in the fractional position of $0 \cdot 17$ to $0 \cdot 23$ (Fig. 1 b).

As shown in Figure 2, the number of labelled cells in the upper half of the crypt column in all cases was extremely small, less than five.

The labelling indices of the eight cases were measured (Table 2). Of 27336 epithelial cells in crypt columns scored, 2369 labelled cells were found. In the three patients with familial polyposis coli, the labelling indices were $8 \cdot 31,8 \cdot 46$, and $8 \cdot 29 \%$, respectively, while in the five patients with non-polyposis

Table 2 Cell kinetic data on background mucosa in eight patients with intestinal neoplasms

\begin{tabular}{|c|c|c|c|c|c|}
\hline $\begin{array}{l}\text { Patient } \\
\text { (patho- } \\
\text { logical } \\
\text { findings) }\end{array}$ & $\begin{array}{l}\text { Cells } \\
\text { in } 50 \\
\text { columns } \\
(n)\end{array}$ & $\begin{array}{l}\text { Cells per } \\
\text { column }(n) \\
(\text { mean }(S D))\end{array}$ & $\begin{array}{l}\text { Labelled } \\
\text { cells } \\
(n)\end{array}$ & $\begin{array}{l}\text { Labelled } \\
\text { cells per } \\
\text { column } \\
(n)\end{array}$ & $\begin{array}{l}\text { Labelling } \\
\text { index }(\%) \\
(\text { mean } \\
(S D))\end{array}$ \\
\hline 1. HM (FPC) & )3237 & $64 \cdot 75(7 \cdot 10)$ & 267 & $5 \cdot 34$ & $8 \cdot 31(3 \cdot 68)$ \\
\hline 2. HK (FPC) & 2982 & $59.65(5.91)$ & 250 & $5 \cdot 00$ & $8.46(2.45)$ \\
\hline 3. IT (FPC) & 3286 & $65 \cdot 73(7 \cdot 91)$ & 270 & $5 \cdot 40$ & $8.29(3 \cdot 21)$ \\
\hline 4. $\mathrm{OC}$ (Ca.) & 3503 & $62 \cdot 83(7.92)$ & 297 & $5 \cdot 94$ & $8.80(3.44)$ \\
\hline 5.SS(Ca.) & 3419 & $68 \cdot 50(3 \cdot 79)$ & 365 & $7 \cdot 30$ & $10 \cdot 72(3.94)$ \\
\hline 6. KK (Ad.) & 4350 & $87 \cdot 01(14 \cdot 63)$ & 369 & $7 \cdot 38$ & $8 \cdot 57(3 \cdot 26)$ \\
\hline 7. HK (Ca.) & 3068 & $61 \cdot 17(5 \cdot 95)$ & 305 & $6 \cdot 10$ & $9 \cdot 73(2 \cdot 85)$ \\
\hline 8. IS (Ca.) & 3491 & $69 \cdot 82(5 \cdot 22)$ & 246 & 4.92 & $7 \cdot 11(3 \cdot 20)$ \\
\hline
\end{tabular}

Abbreviations used: FPC, familial polyposis coli; $\mathrm{Ca}$, adenocarcinoma of the colon; Ad., adenomas of the colon.
Labelled cells $(\%)$

2.5

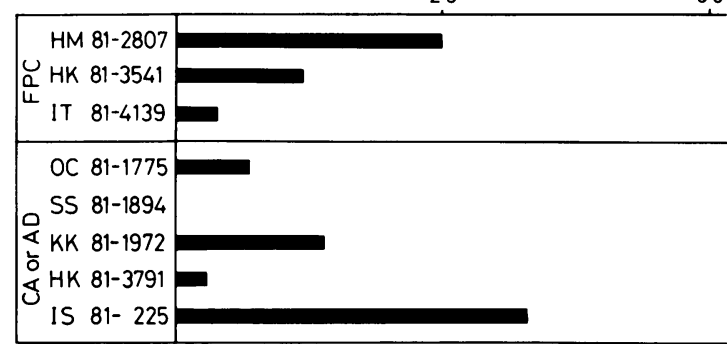

Fig. 2 Histogram of percentages of labelled cells in the upper half of the crypt column in eight cases. Abbreviations used: $C A$, adenocarcinoma of the colon; $A D$, adenoma of the colon; FPC, familial polyposis coli.

cancer or adenomas, they were $7 \cdot 11$ to $10 \cdot 72 \%$. The mean labelling index of the three patients with familial polyposis coli was $8 \cdot 35 \%(3 \cdot 17)$ and that of the five patients with non-polyposis cancer or adenomas was $8 \cdot 55 \%(3 \cdot 20)$. The difference between the values in the two groups was not significant.

\section{Discussion}

In the normal intestinal mucosa, epithelial cells show continuous proliferation, migration, and desquamation. ${ }^{11}$ The turnover time of epithelial cells in the small intestine is approximately two or three days and this rapid turnover is considered to explain, in part, why epithelial neoplasms are rare in the small intestine. ${ }^{12}$ The colonic epithelium is also actively renewed, with a turnover time of about five to eight days in $\operatorname{man}^{1314}$ and 4.85 days in mice. ${ }^{10}$ Thus if a transformed cell appears in the proliferative zone of the crypt, even if it proliferates continuously, the resulting transformed cells should be desquamated from the mucosal surface within eight days. If this is the case, epithelial tumours of the large intestine should be rare. But, in fact, benign or malignant neoplasms in the large intestine are not so rare.

As an explanation for this discrepancy, several investigators ${ }^{1-5}$ have proposed that an upward shift of the proliferative zone of the crypts to the mucosal surface occurs before adenomas develop, so that the transformed cells can proliferate, settle and grow into adenomas in the colonic mucosa. No apparent derangement of the proliferative zone of the crypt was observed, however, in patients with familial polyposis coli by Bleiberg et al ${ }^{15}$ or in animals we treated with chemical carcinogens. ${ }^{16}$ Therefore, we proposed that tumours develop first as microscopic 'buds of adenomas' and then form single gland adenomas in the colonic mucosa without derangement of the proliferative zone of the crypts. ${ }^{8}$ 
In the present investigation we observed similar labelling distributions in patients with familial polyposis coli or those with non-polyposis cancer or adenomas and no upward shift of the active proliferative zone in either group. The non-proliferative zone was also well preserved in all eight patients.

In the present study, the mean labelling index of the three patients with familial polyposis coli was $8.35 \%(3.17)$ and that of the five patients with nonpolyposis cancer or adenomas was $8.55 \%(3 \cdot 20)$. These values are comparable with those reported by Maskens and Deschner of $9.8 \%(1.2)$, values expressed as mean (SE) for a cancer group and $7.9 \%$ $(0 \cdot 9)$ for a control group. ${ }^{17}$ Bleiberg et al reported that the labelling index values of the healthy mucosa in two of their patients with familial polyposis coli were $10.0 \%$ and $10.8 \% .^{15}$ In studies on the in vitro cell kinetics of colonic mucosa, Hayashi et al obtained a similar value of $11.1 \%$ for normal mucosa, ${ }^{18}$ but Lipkin and colleagues reported a much higher labelling index $(18 \%-12 \%) .{ }^{19}$

In vitro autoradiography is the most commonly used method for studying cell kinetics, because labelling is relatively comparable with in vitro labelling and the method is safe. ${ }^{20-22}$ This method has the following limitations, however, (1) The exact sites and lesions in the colonic mucosa taken for biopsy are usually obscure macroscopically. (2) The specimens must be less than $1 \mathrm{~mm}$ thick and $5 \mathrm{~mm}$ wide to allow adequate $\left[{ }^{3} \mathrm{H}\right] \mathrm{dT}$ Thd diffusion to obtain a reliable labelling index. ${ }^{21}$ (3) The specimens are so small that the relationship of the adenoma and the surrounding mucosa cannot be microscopically well defined.

The validity of ex vivo autoradiography was shown in our study on the rat gastrointestinal tract in which the labelling distribution and labelling index were comparable with those observed by in vivo autoradiography. ${ }^{23}$ Ex vivo autoradiography overcomes the inevitable limitations of in vitro autoradiography. By subjecting routine specimens of surgical material to microautoradiography, we can select crypt columns with no pathologic lesions in large well oriented sections $(2 \times 4 \mathrm{~cm})$. Thus we can omit the hyperplastic glands observed in the background colonic mucosa of cases of ordinary colonic cancer or familial polyposis coli and the hyperplastic transitional mucosa adjacent to carcinoma ${ }^{24}$ from experimental materials.

Ito et $a l^{25}$ studied the cell kinetics of duodenal cancer induced by a chemical carcinogen in mice and observed that the kinetic parameters of background duodenal crypts in the experimental group were almost the same as those in the control group. They observed that the carcinoma cells developed in the duodenal crypts and invaded the surrounding mesenchymal tissue of the villi by 'lateral invasion' ${ }^{26}$ It is interesting that the mechanism of development of neoplasms with normal cell kinetics of the background duodenal mucosa in mice seems very similar to that noted in man in our present results.

Based on our present results and previous findings that colonic adenomas appear as 'buds of adenomas', ${ }^{8}$ we suppose that the buds of adenomas develop through the following processes: (1) A transformed cell appears in the colonic epithelium at the lower part of the crypt. (2) It divides several times, moving upwards with migration of the epithelial cells of the crypt. (3) A small number of transformed cells break through the basement membrane of the crypt, sprout into the lamina propria mucosae, and are identified as buds of adenoma in the middle part of the crypt.

Our present results disclosed no kinetic difference in the colonic crypts of the patients with familial polyposis coli and those with non-polyposis cancer or adenomas. Patients with familial polyposis coli, however, are prone to have numerous colonic neoplasms. Studies of the processes by which the buds of adenomas appear in the colonic crypts should provide important clues to the aetiology of colonic adenomas in patients with familial polyposis coli.

\section{References}

1 Cole JB, McKalen A. Studies on the morphogenesis of adenomatous polyps in the human colon. Cancer 1963; 16: $998-1002$.

2 Wiebecke B, Brandts A, Eder M. Epithelial proliferation and morphogenesis of hyperplastic adenomatous and villous polyps of the human colon. Virchows Arch [Pathol Anat] 1974; 364: 35-49.

3 Lipkin M. Phase 1 and phase 2 proliferative lesions of colonic epithelial cells in diseases leading to colonic cancer. Cancer 1974; 34: 878-88.

4 Maskens AP. Histogenesis of adenomatous polyps in the human large intestine. Gastroenterology 1979; 77: 1245-51.

5 Deschner EE, Lipkin M. Proliferative patterns in colonic mucosa in familial polyposis. Cancer 1975; 35: 413-8.

6 Lane N, Lev R. Observations on the origin of adenomatous epithelium of the colon - Serial section studies of minute polyps in familial polyposis. Cancer 1963; 16: 751-64.

7 Kato Y, Nagasako H, Kino I. Mode of initiation of colonic adenoma - A serial section study. Trans Soc Pathol Jpn 1976; 65: 220.

8 Nakamura S, Kino I. Morphogenesis of minute adenomas in familial polyposis coli. $J$ Natl Cancer Inst 1984; 73: 41-9.

9 Nakamura S, Kino I, Baba S. Ex vivo autoradiography of the human gastrointestinal tract: A new approach to cell kinetic studies of surgically removed tumourbearing organs. Gann 1983; 74: 116-21. 
10 Tsubouchi S. Kinetic analysis of epithelial cell migration in the mouse descending colon. Am J Anat 1981; 161: 239-46.

11 Deschner EE, Lipkin M. Proliferation and differentiation of gastrointestinal cells in health and disease. In: Lipkin M, Good RA, eds. Gastrointestinal tract cancer. New York: Plenum Medical Book Corp, 1978: 3-27.

12 Rijke RP. Some speculations on control mechanisms of cell proliferation in intestinal epithelium. In: Appleton $\mathrm{DR}$, Sunter JP, Watson AJ, eds. Cell proliferation in the gastro-intestinal tract. Kent: Pitman, 1980: 57-65.

13 Cole JB, McKalen A. Observation of cell renewal in human rectal mucosa in vivo with thymidine- $\mathrm{H}^{3}$. Gastroenterology 1961; 41: 122-5.

14 MacDonald WC, Trier JS, Everett NB. Cell proliferation and migration in the stomach, duodenum and rectum of man: Radioautographic studies. Gastroenterology 1964; 46: 405-17.

15 Bleiberg $\mathrm{H}$, Mainguet $\mathrm{P}$, Galand $\mathrm{P}$. Cell renewal in familial polyposis: Comparison between polyps and adjacent healthy mucosa. Gastroenterology 1972; 63: 240-5.

16 Nakamura S, Kino I. Morphogenesis of experimental colonic neoplasms induced by dimethylhydrazine. In: Pfeiffer CJ, ed. Animal models for intestinal disease. Boca Raton: CRC Press Inc, 1985: 99-122.

17 Maskens AP, Deschner EE. Tritiated thymidine incorporation into epithelial cells of normal-appearing colorectal mucosa of cancer patients. J Natl Cancer Inst 1977; 58: 1221-4.

18 Hayashi T, Yatani R, Apostol J, Stemmermann GN. Pathogenesis of hyperplastic polyps of the colon: A hypothesis based on ultrastructure and in vitro cell kinetics. Gastroenterology 1974; 66: 347-56.

19 Lipkin M, Bell B, Sherlock P. Cell proliferation kinetics in gastrointestinal tract of man. I. Cell renewal in colon and rectum. J Clin Invest 1963; 42: 767-76.

20 Denekamp J, Kallman RF. In vitro and in vivo labelling of animal tumours with tritiated thymidine. Cell Tissue Kinet 1973; 6: 217-27.

21 Steel GG, Bensted JPM. In vitro studies of cell proliferation in tumours - I. Critical appraisal of methods and theoretical considerations. Eur J Cancer 1965; 1: 275-9.

22 Oliver R, Lajtha LG. Hazard of tritium as deoxyribonucleic acid label in man. Nature (Lond) 1960; 186: 91-2.

23 Nakamura S, Kino I, Baba S. Ex vivo autoradiography of the human gastrointestinal tract. In: Kawai K, ed. Gastric mucus secretion. Tokyo: Igaku-tosho-shuppan, 1987: 18-27.

24 Filipe MI. Value of histochemical reactions for mucosubstance in the diagnosis of certain pathological conditions of the colon and rectum. Gut 1969; 10: 577-86.

25 Ito M, Yamada S, Matsuyama M, Nagayo T. Cell kinestics of duodenal cancer induced by $\mathrm{N}$-ethyl- $\mathrm{N}$ nitro-N-nitrosoguanidine in $\mathrm{C} 3 \mathrm{H} / \mathrm{He}$ mice. Gann Monogr Cancer Res 1980; 25: 89-99.

26 Matsuyama M, Nakamura T, Suzuki H, Ito M, Yamada $\mathrm{S}$, Nagayo T. Early lesions in carcinogenesis by $\mathrm{N}$-ethylN'-nitro-N-nitrosoguanidine in mouse duodenum. In: Faber E, et al, eds. Pathophysiology of carcinogenesis in digestive organs. Tokyo: Univ of Tokyo Press/ Baltimore: Univ Park Press, 1977: 269-83. 